\title{
From Cover to Cover: Every Cover has a Story
}

\author{
Feryal CUBUKCU \\ Dokuz Eylul University, Turkey \\ Meryem AYAN \\ Pamukkale University, Turkey
}

Wolfgang Iser's "biactive approach" asserts an active participation between text and reader in the creation of the meaning that requires a communication between the text and the reader. The first communication between the text and the reader starts with the book cover that attracts the interest of the reader at first sight. Then the reader wonders about the relation between the cover and the text. Thus the first communication between the reader and the text begins together with the visual interpretation of the narrative discourse (text) that is multifaceted because of the convolution of the world of the author and world of the reader, which leads to the construction of the factual and the fictional worlds forming the "extratextual reality" (Booker 46). The repertoire of the extratextual reality, as a key to the text and beyond the text, helps to establish a common basis between the author and the text, the text and the reader, the reader and the cover that has a "pictorial story" rather than a fictional expression that diversifies the interpretations related to the texts because the text in "the process of reading is not seen as an end in itself but as a trigger for creative activity of the reader" (Booker 41) and the cover of the book is the creative image attracting the attention of the reader who works his or her "way through a text, gradually constructing a response to the text in the reading process" (Booker 44). The cover of the book is a product of interactional act between the text and the subjective consciousnesses of the reader that implicitly or explicitly presents the major event or character in the novel. Indeed, there are different interpretations for a single text and they bring into different aspects of textual meaning. The diversity of interpretations do support and reinforce the meaning of the text. Hirsch calls this as "the babel of interpretations" (128) and maintains the fact that all interpretations are different warrants neither the sanguine 
belief that all plausible interpretations are helpful and compatible nor the hopeless proposition that all interpretations are personal, temporal and incommensurable.

Biactive criticism offers a means of exploring agency in a productive way. Iser characterizes bioactive criticism as "text and reader as acting together; the text sets limits and the reader responds to it within those limits and within the limits of her or his subjectivity, ideology, psychological make up, literary competence and so forth (130). To this extent writing is an act of reading and vise-verse; and it is from this act of writing/reading that perspective emerges (Waite 22). Perspective is an act of transformation of one complex term or another. Actually both readers and texts set limits: one through presentation and the other through subjective and ideological perspectives. The meaning emerges through the interaction between the reader and the text. Biactive falls between the two extremes "text-active" and "reader-active" (129-130). Iser argues that although the reader fills in the gaps, it is the author's intentional acts inscribed in the text that impose restrictions and conditions to the relativistic analyses of the text. In the same vein, it is the designer of the cover who sets restrictions upon the reader and mis/leads them in terms of textual, financial and political concerns.

Actually, no interpretation is free but it is dependent upon acquisitions such as language, generic, norms, social patterns and beliefs (Scholes 150), however, Scholes holds that more than interpreters, the words in the text and the images on the cover lead people to think and interpret differently. Different even conflicting assumptions may preside over any reading of a single text or looking at a single book cover by a single person, it is these differences within the reader, who is never a unified member of a single unified group. The freedom of the reader to interpret a text or a cover is constrained by language and signs or symbols. A literary event is important as long as readers are interested in it and eager to read and interpret and find similarities between the text, the cover and their own life. The literary experience of the reader is a combination of "individual consciousness" by Wellek, "collective consciousness" by Jung and "collective ideology" by Jacobson. A literary work is not something "absolutely new in an informational vacuum, but predisposes its readers to a very definite type of reception by textual strategies, overt and covert signals, familiar characteristics or implicit allusions. It awakens memories of the familiar, stirs particular emotions" (Jauss 63). Covers also are created by different pictorial strategies, overt and covert signals that stir emotions and give clues about the text. However, sometimes the pictorial reading of the cover misleads the reader and the reader has difficulty in 
interpreting what the cover symbolically implies and what the text presents or fictionally expresses.
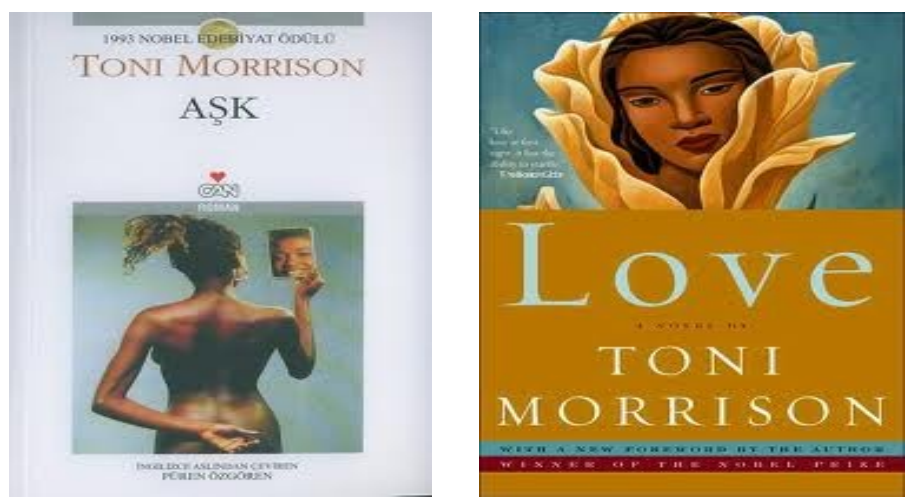

One of the leading proponents of the Reader Response Theory, Rosenblatt (1995), states that "words in the text" and "images on the cover" associate special meanings or different expectations because individually the reader "largely determines what the work communicates to him"(30). Thus, the reader brings personality traits, memories of past events, present needs and preoccupations, a particular mood of the moment, and a particular physical condition and emotions. These and many other elements "in a never-to-be-duplicated combination determines his or her response to the peculiar contribution of the text" (30-31) and the cover of the book. As is seen above, the covers of "Love" are different in Turkish and English. A reader may be stimulated to remember a related personal experience and the images and schema drawn upon the covers differ: in the Turkish cover, the schema is about the back of a naked woman conoting sensuality whereas the English cover displays a black girl in a flower (fluer-de-lis) implying virginity and deflowering of a young girl.

Despite the mix of private and public aspects of meaning in each stance, the two dominant stances are clearly distinguishable: someone else can read a text differently for us in the cover, and acceptably paraphrase, but no one else can read aesthetically - that is, experience the evocation of - a literary work of art for us (125) because the interpretation of a text and cover aesthetically differs from perspective to perspective regarding the cultural, literal and individual backgrounds; therefore, broad range of textual interpretations and different reactions to the texts might appear. The meaning of a text is not an entirely subjective matter, of course, and it is crucial that responses be grounded in the text itself and in the context in which the text is read. One way of guarding against 
people "running wild" is to make sure that there's a community restraint on interpretation. Even though an individual reader's reactions are based on their own "schema" (the expectations that arise from personal experiences), they will realize that not everyone shares that same perspective. Thus, the book covers of Toni Morrison in Turkey and the USA are diversified, one emphasising the sensual love and the other spiritual love.
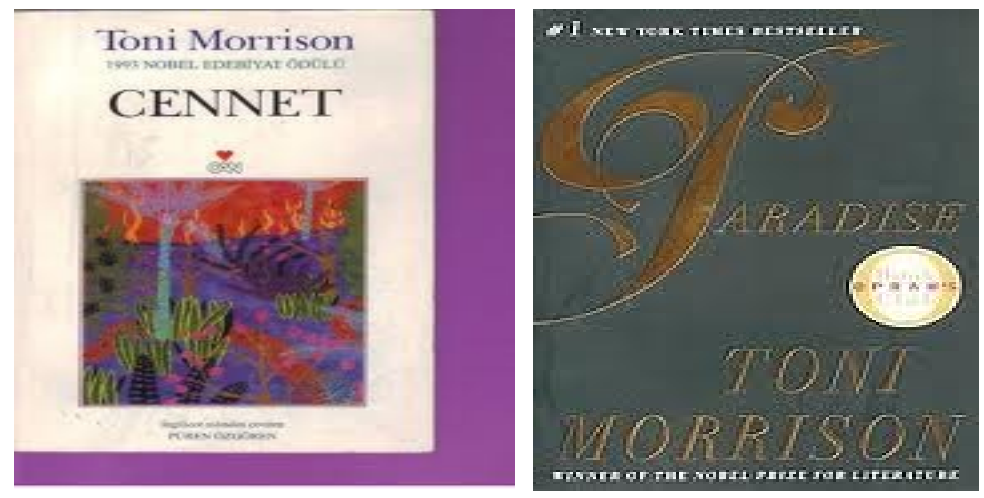

Apart from gazing at the cover or reading the text, readers also bring their imagination to the text that reshapes the cover image and the interpretation of the text. In the above covers, the Turkish one has the image of paradise symbolized in reed, orange, blue, dark blue colors and a natural landscape whereas the English cover only has the word "Paradise" on a dark greyish background implying the skin color of the African American people. Iser (1989) focuses on the notion of "aesthetic response", which involves not only the interaction between reader and text but also the unique, imaginative capacity that the reader brings to the text. Iser describes aesthetic response as follows: "Aesthetic response is...to be analyzed in terms of a dialectic relationship between text, reader, and their interaction. It is called aesthetic response because, although it is brought about by the text, it brings into play the imaginative and perceptive faculties of the reader, in order to make him adjust and even differentiate his own focus" (x). The English cover's appealing to the imagination of the reader substantiates Iser's contention that the work itself is not defined by the text itself or by the reader's interpretations alone, but "must be situated somewhere between the two. The Turkish cover's rainbow of colors indicates a religious and spiritual dimension of "Paradise" for its readers.

Actually, the "convergence of text, reader and the schema brings the literary work into existence" (275), because the reader uses the various perspectives offered him by the text in order to relate the patterns and the "schematized views" to one 
another, he sets the work in motion, and this very process results ultimately in the awakening of responses within himself. The determinate features of the texts together with the cover images- here the picture of paradise in the Turkish book and the lack of the picture in the English one - invite the reader to participate in a game of imagination upon which it imposes certain constraints: the text's "unwritten part ... stimulates the reader's creative participation" (276).

Iser's model is very much based on the notion of communication between the reader and the text. Iser argues that literary texts are filled with indeterminacies and gaps that must be filled in by readers to complete the work by granting the reader a more creative role in the realization of the text than does Fish's affective stylistics. Iser's approach, then, might be referred to as "biactive" in that it provides for an active participation on the part of both text and reader in the creation of meaning. Iser's "implied reader" thus has a great deal in common with Fish's "informed reader". Both critics place a great deal of emphasis on the surprises texts present to unsuspecting readers while simultaneously assuming a great deal of knowledge and experience on the part of readers. As Iser continues whatever we have read sinks into our memory and is foreshortened. It may later be evoked again and set against a different background with the result that the reader is enabled to develop hitherto unforeseeable connections, whatever we see on book covers or whatever we observe is shaped by our background experiences and absorbed into our memory. Iser contends that the " "picturing' . . done by our imagination is only one of the activities through which we form the 'gestalt' of a literary text" (282). In addition to the "process of anticipation and retrospection" (283), the reader will engage in a "process of grouping together all the different aspects of a text to form the consistency that the reader will always be in search of" (283): the reader will always "strive, even if unconsciously, to fit everything together in a consistent pattern" (283). By "grouping together the written parts of the text, we enable them to interact, we observe the direction in which they are leading us, and we project onto them the consistency which we, as readers, require" (285). It is possible to apply biactive approach to cover interpretation as seen below Figure 1.

Cover (visual text)

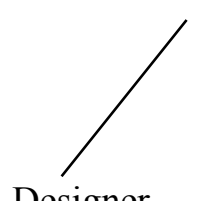

Designer

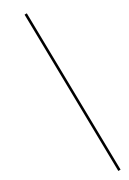

Reader (viewers)
Text (literary text)

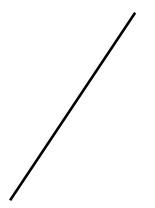

Author

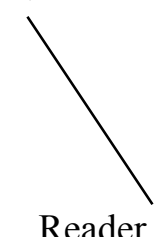

Reader 
Figure 1. Comparison of cover and text interpretations

1) In the first figure the meaning is created by the reader during the viewing process and in the second figure the meaning is created by the reader in the reading process.

2) The meaning changes from cover to cover and in the second the meaning changes from text to text.

3) Interpretation changes from reader to reader in both processes

4) Every cover has a story and every text has a plot

5) Cover provides visual communication and the text provides literal communication between between the text and the reader

6) Both visual and literary texts carry cultural codes which invite viewers to decode the them

7) The viewer supposes the plot of the text and the reader creates the meaning of the text.

8) Preexisting expectations versus pre, while and post reading expectations

9) Visual reader versus implied or informed reader

Thus, in reading "every text and cover we read draws a different boundary within our personality, so that the virtual background (the real 'me') will take on a different form, according to the theme of the text concerned" (293-294). The need to decipher gives us the chance to formulate our own deciphering capacity. The production of the meaning of literary texts - when discussed in connection with forming the 'gestalt' of the text -entails the possibility that we may formulate ourselves and meanings overy or covert in the texts and covers which are culturally imposed through our schemas and so discover what has previously seemed to elude our consciousness.

\section{References and notes:}

Fish, Stanley. Is there a text in this class?. MA: Harvard University Press, USA, (1980) 
Hirsch, E . D. Validity and Interpretation. New Haven:Yale (1967)

Jauss, H. R Literary history as a Challenge to Literary Theory in New directions in Literary History ed R. Cohen . NY : Routledge, (1974)

Iser, W. Prospecting: From Reader Response to Literary Anthropology. Baltimore, MD: The Johns Hopkins University Press, (1989).

Iser, Wolfgang. "The Reading Process: a Phenomenological Approach." The Implied Reader.Baltimore: Johns Hopkins UP, 1974. pp. 274-294.

Rosenblatt, L. (1938). Literature as Exploration. New York: Appleton-Century; (1968). New York: Noble and Noble; (1976). New York: Noble and Noble; (1983). New York: Modern Language Association; (1995). New York: Modern Language Association.

Rosenblatt, L. "The aesthetic transaction". Journal of Aesthetic Education, 20 (4), (1986).pp 122-128.

Scholes, R Textual Power: Theory and Teaching of English. New Haven: Yale University Press. (1985)

Waite,J. Unpublished doctoral s thesis Identifying Agency: The Construction of Rhetorical Agency in Foxfire 2007

\title{
Summary
}

\section{From Cover to Cover: Every Cover has a Story}

\author{
Feryal CUBUKCU \\ Dokuz Eylul University, Turkey \\ Meryem AYAN \\ Pamukkale University, Turkey
}

Reading is a visual and mental communication between a reader and a text because the reader's knowledge, experience and expectation help fill the gaps within an incomplete text. Namely, the reader's visual and mental communication with the text requires supplemental information such as personal experience, perspective, interest and knowledge so that the incomplete narrative presenting instructions for the reader can be interpreted. In the communication between the reader and the text as Wolfgang Iser asserts "the reader plays a more creative role in the interpretation of the text because the text provides guidance and instructions but places limitations on its own interpretation. Thus, for Iser the reader plays a more active participation on part of both the text and the reader in 
interpretation and creation of rich meaning. Iser's approach referred to as "biactive approach" is based on the communication between the reader and the text in which the reader's own experiences and supplementary information is required in order to create meaning (Booker 45). Even the cover of the book that opens the doors to the deeper meaning hidden between the lines within the pages requires a biactive participation because the first communication between the text and the reader starts with the representation of the cover that lures the reader into the elicitation and interpretation of the narrative discourse. The cover that has a "pictorial story" rather than a "fictional expression" establishes the visual communication between the reader and the text at first sight. In the frame of Iser's "biactive approach" the covers of Toni Morrison's novels published in USA and translated in Turkey will be compared and contrasted focusing on the cover images and the biactive participation between reader and book covers that tell stories of their own extratextual realities differing from cover to cover.

Key Words: biactive, reader response, cover images 